\title{
Investigating Individual Voice in Thematic Development in Academic Assignments Written by Iraqi and Australian Postgraduate Students
}

\author{
Ali Jabbar Al BAKAA (Corresponding author) \\ School of Education, Monash University, Melbourne, Australia \\ PO Box 6, Clayton Campus, Victoria 3800 \\ Tel: +9647801031703Ｅ-mail: alibka@hotmail.com
}

Received: November 8, 2014 Accepted: December 1, $2014 \quad$ Published: December 1, 2014

doi:10.5296/ijele.v3i1.6710 URL: http://dx.doi.org/10.5296/ijele.v3i1.6710

\begin{abstract}
The notion of individual voice is an important aspect of functional grammar in student's academic writing, as taking a stance is one of the most important requirements of academic assignments at Australian universities. Jalilifar (2009), for instance, demarcated thematic development as an element which plays a crucial role in the message function of language. This raises an important question as to how postgraduate students as academic writers deal with the function of thematic development in terms of individual voice in demonstrating a critical argument. Unfortunately, few studies have focused on this aspect in relation to Iraqi postgraduate students in the Australian context of writing. To this end, four academic assignments were selected and analysed to uncover the similarities and differences in the function of the thematic development, and to determine whether and how students of different cultures stamp their individual voice on the text through the thematic development elements of their academic arguments. Using Eggin's (2004) model of thematic development, this paper concerns a corpus of four academic assignments from four Masters Students (two Iraqi and two Australian students). The data analysis revealed marked differences in these four academic assignments regarding the functions of thematic development as a starting point for their academic argument. The findings showed that the Iraqi postgraduate students struggled both in expressing their individual voice through the function of thematic development, and in supporting their claims with evidence from what they had read. The study presents a critique of Kaplan's claims (1966) that the zig-zag pattern is a characteristic of Arab students' writing, in contrast to the linearity of English writers. Instead it found that the Iraqi non-native writers of English were writing their assignments by copying and writing what they read from their texts and one reason for this was that the element of individual
\end{abstract}




Mll Macrothink

voice has not been emphasized in the Iraqi education system.

Keywords: Individual voice, thematic development, Iraqi non-native writers of English, Australian native writers of English, academic writing 


\section{Introduction}

In recent years, the notion of thematic development has attracted significant attention from many researchers from many different contexts of writing teaching (Berry, 1995; Eggins, 2004; Ebrahimi, 2012; Mellos, 2011; Wang, 2007). These researchers have identified the kinds of challenges that undergraduate and postgraduate students face in academic writing. For example, research with Arab postgraduate student writers has illustrated that a lack of text cohesion and coherence is clearly visible in their academic writing (Ahmed, 2010). Although Kaplan (1966) suggested this is linked to cultural modes of expression, other writers suggest this is due to the method of teaching writing in their home countries (Alagozlu, 2001; Al-Khasawneh, 2010; Barnawi, 2011; Rabab'ah, 2003).

The flow of thinking and expression through the aspect of theme and rheme has also been investigated in academic writing. Lewthwaite (2010), for instance, studied the coherence of Emirates students' writing, and argued that the "flow of thinking and expression" in any academic writing "is usually established by writers using cohesive devices, multi-word expressions and by developing the ideas (themes) with restatement or logical extensions" (rhemes) (p. 1). Most of these researchers addressed issues of function of textuality and similarities and differences in writing these aspects (Ebrahimi, 2012; Mellos, 2011; North, 2005; Wang, 2007). Yet, despite all these studies regrading the aspect of theme and rheme as a core of writing competence, little research has examine the function of thematic development in terms of individual voice in academic assignments written by Iraqi and Australian postgraduate students and its possible relation to their academic experience.

\subsection{Individual Voice and Academic Writing}

Individual voice in academic writing refers to authorial identity or authorial presence (Ivanic \& Camps, 2001; Viete \& Phan Le Ha, 2002) rather than "a straightforward citation of other people's ideas" (Alagozlu, 2001, p. 121). Alagozlu (2007) analysed the element of critical thinking in argumentative essays written by Turkish EFL students with the purpose of investigating whether the students displayed the elements of critical thinking or voice to form robust arguments. The results of the study showed that the Turkish EFL students were struggling noticeably in expressing their individual voice and claims, and they used too many unsupported claims in these essays. More specifically, the students did not construct arguments comprising claims with reasons and evidence from the texts they had read, and the essays they wrote revealed that they were just copying or writing what they had read rather than filtering them through their arguments. In agreement with Alagozlu's (2001) viewpoint, Barnawi (2011) discussed the place for critical thinking and self-voice in a college EFL writing classroom from the perspective of post-process theories of composition. The results showed that the lack of critical thinking and self-voice in EFL students' academic writing was because the elements of critical thinking and self-voice were not developed in their traditional education systems in their country of origin. Additionally, EFL teachers had not required their students to be critical and authoritative in writing, as they had not been taught to think critically and independently in their first language.

While developing individual voice has been neglected in Arab and non-Arab EFL writing 
contexts, writers in some English speaking higher education contexts are required to pay great attention to this aspect in writing their English academic assignments. This matter has been discussed over the last decades by many academic researchers in a variety of writing teaching contexts (Ivanic \& Camps, 2001; Ramanathan \& Atkinson, 1999; Viete \& Phan Le Ha, 2002). Ramanathan and Atkinson (1999), for instance, mentioned that

"Achieving the cultural goal of independence requires construing oneself as an individual whose behaviour is organized and made meaningful primarily by reference to one's own internal repertoire of thoughts, felling, and action, rather than by reference to the thought feelings, and actions of others.... in contrast, many non-western cultures insist... on the fundamental connectedness of human beings to each other.... A normative imperative of those cultures is to maintain this independence among individuals" (p. 51).

These writers emphasise the need for establishing individual academic voices in ESL writing contexts. However, this might pose a much greater challenge for international students as these students are socially constructed by their home context. From my personal experience as an Iraqi EFL teacher and student, I only got to know about individual voice or a grammar of authority when I was first studying my Graduate Diploma of TESOL at an Australian university. Given the lack of prior understanding of this, Iraqi postgraduate students struggle to achieve effective, individual voice and coherence argument in academic writing, despite the need to meet these requirements at postgraduate level in Western academic cultures.

Ivanic and Camps (2001) investigated lexical, syntactic, and organisational and material aspects of writing by examining six Mexican graduate students' academic assignments. The goal was to explore voice as self-representation through Halliday's (1985) model of the three macrofunctions of language. These include "Positioning in terms of the writer's way of self-representation in the world" (ideational positioning); positioning in terms of their relative authoritativeness or tentativeness that is interpersonal positioning "in terms of writers' relationship with their readers" and textual positioning as the way of turning meaning into texts of their own or of others (p. 4). The study showed that in interpersonal positioning, the students did not present themselves very clearly, thus their authority appeared to be invisible. The writers conveyed their individual voice in these assignments about themselves by using words such as "they", he", or "she" to represent their ideas and voice in general. On the other hand, in terms of textual positioning, the students used "we" to create the immediacy of the spoken language to invite interaction between writer and reader. Some students presented their textual positioning by presenting signposting expressions as elements of a "reader-considerate" voice to ensure their text gave fully explicit signals to the reader. As with Ivanic and Camps (2001), Viete and Phan Le Ha (2002) in a different study explored the representation of self in Phan's novice research writing. The results showed that in her writing, Phan was authoritative towards her reader through the use of a highly personalised argument based on her own experiences. She cited from her own insider experiences, even though the use of "I" - the first person - was unusual at the time in academic writing.

\subsection{Individual Voice and Thematic Development in Academic Writing}

Theme and rheme, which operate as a grammar of authority, have been used as a tool to view 
how students construct their individual voice in writing academic texts. Kamler and Thomson (2006), for instance, in their book entitled Helping doctoral students write, have argued that doctoral researchers must guide their readers through their argument, and must be careful of what to say through thematic structure in order to provide coherent arguments. These authors point out that the writer's authority or voice in writing is very important since it provides a coherent navigation for readers.

Wang (2007) explored the relationship between theme and rheme organization in English texts written by sophomores majoring in politics from a South-Eastern University in China. The results showed that "students' weaknesses in their argument were due to problems with thematic development" in their written texts (p.174). Moreover, the lack of thematic development made their written text read "like a list" as there was a "lack of further development in the rheme" (p. 171). This study has also shown that this is the characteristic of descriptive and narrative texts, which use a constant progression pattern, where in an "argumentative text" there is a need for "cross-referential links from the rheme element of one clause to the theme of the next clause" (p. 171).

In agreement with Wang's (2007) viewpoint, Khuwaileh and Al Shoumali (2000), in a comparative study of Arab student's academic writing in both Arabic and English language, noticed the linguistic weakness in their students writing (p. 175). One aspect of this is the lack of connection between sentences and paragraphs such that the text looks like a list of sentences rather than logical linking of ideas by discourse markers such as "firstly", secondly", "next". Likewise, Rusdinoor (2009) pointed out that applying the patterns of thematic progression is one way to improve the cohesion of the students' expository writing, yet, if writers overuse the strategy where the same theme is chosen over several clauses, their text will read like a list. This is due to the lack of further development of rheme in the preceding sentences into theme in those that follow (p. 6). Kamler and Thomson (2006) also, noted that "text in which theme never varies will not only be boring to read or listen to, but indicates a text that is going nowhere" (p. 120).

Other important studies have emphasized the need to understand the link between local and global writing requirements. Hyland (2007), stated that successful writers are those who share professional contexts in academic writing with their readers, as this will help them to make predictions on how readers are likely to react to their writing (p.176). Like Hyland (2007), Mellos (2011) mentioned that academic texts often use zigzag patterns to connect their ideas between sentences and paragraphs to develop their ideas (p. 90). In the same line of argumentation, the use of multiple rhemes is another highly effective function, and constitutes valuable technique that skilled writers can use to enhance the cohesion and coherence in their piece of writing. Competent writers can deliberately pattern their sentences so as to connect their ideas through cohesion in their written discourse (Eggins, 2004; Krisnawati, 2013). By contrast, unskilled writers lack the use of zig-zag progression patterns and overuse theme reiteration where the same elemental theme is repeatedly presented adjoining clauses in their academic writing, which makes their text seem disconnected and not authoritative, while they should have picked up the rheme of one clause to become the theme in the following text (Mellos, 2011; Wang, 2007). The implication of the research 
mentioned above is that the selection of themes can affect how texts are linked and patterned from one sentence to another to form cohesion and authority in voice.

\section{Method}

\subsection{Corpus}

This study used the corpus of four academic assignments written for the course of Master of TESOL by native (Australian) and non-native (Iraqi) writers of English to compare the similarities and the differences regarding the function of the thematic development and the purpose of individual voice. One segment on the same topic has been chosen across these assignments to permit fruitful comparison. The data came from assignments written for the unit "Language, society and cultural differences" in the Master of Education (TESOL) at Monash University. This unit is a fundamental and critical unit in the course. It aims to develop the capacity of self-directed learner-researchers in classes and on line activities to explore the ways that language, society, and cultural difference are related to each other, and why this matters to educators working in schools, universities and technical colleges (Faculty of Education, 2013). It has been designed to cover topics around language, culture, identity, and differences; English language education in local (Australian), and global contexts, and the political and social implications of the globalisation of English in issues related to immigration and cultural difference in multiple contexts (Faculty of Education, 2013).

The unit is divided into three sections. The first section is concerned with the idea of language, cultural and political practices. In this particular section the students are required to use Hall's notion of representation in order to understand language and cultural difference by giving examples from their own experience. In this task, students have to demonstrate a critical understanding of the complexities of Hall's argument. In the second section, the unit extends its readings to discuss the aspect of identity within language learning and teaching. Recent debates regarding English as an international language are also referred to in this unit, including issues raised by significant scholars such as Canagarajah, (1999), Kramsch, (1998), Pierce (1995), and Phan (2008). Students are expected to develop their own individual voice in writing their academic assignments. The third section of the unit debates issues related to language policy, curriculum and pedagogy in Australian, and overseas contexts. Studying this particular unit, students are expected to express their authorial voice, and use critical thinking to construct good academic assignments.

\section{Analytical Model}

The notion of thematic progression was first introduced by the Linguist, Danes (1974), in order to conceptualise the role of theme in text organization and construction. Danes' model was developed by Eggins (2004). This study has adopted Eggin's Model of Thematic Development, and the rationale behind this selection is that this is the most updated model of analysis.

Using the model described in Eggins (2004), I categorized the assignments according to their use of the following three patterns: (1) Theme reiteration $<\mathrm{T}-\mathrm{R}>$, (2) the zig-zag pattern $<\mathrm{Z}-\mathrm{Z}>$, and (3) the multiple-rheme pattern $<\mathrm{M}-\mathrm{R}>$. 
(1) Theme reiteration is "when the same element occurs regularly as theme in text" Eggins (2004, as cited in Mellos, 2011, p. 9). This pattern can make the written segment difficult to read since there is a lack of thematic development.

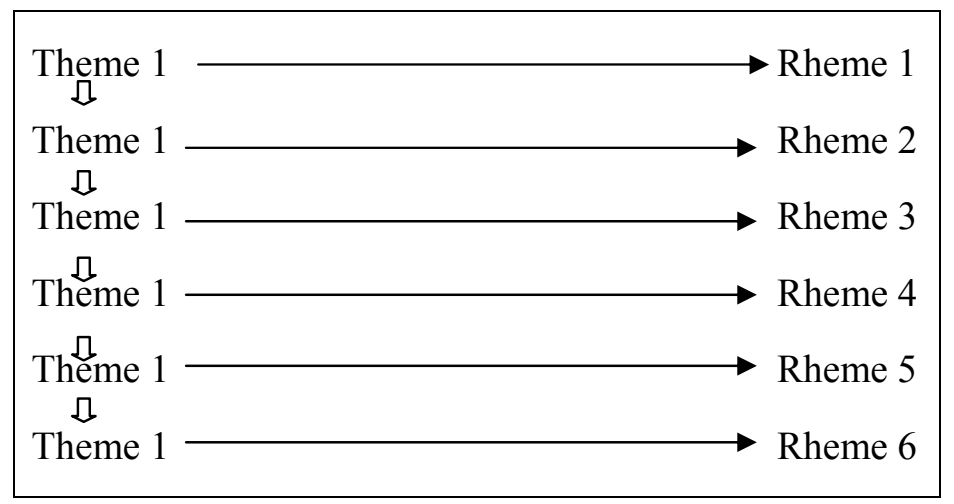

Figure 1, theme reiteration TP, Student Ir 1

Example: "Hall <T-R> (1997) argues that cultural identity is represented through producing and exchanging meanings. Hall $<$ T-R $>$ (1997b) proposed the term of "Diaspora" to refer to any migrants people that share common ethnic identity such as the African Diaspora in Europe. Hall $<\mathbf{T}-\mathbf{R}>$ refers to this diaspora and mentions that all cultural practices and forms of representation are putting the issue of cultural identity in question of" Who is this emergent" (p. 392)."

(2) Zig-zag pattern occurs when "an element which is introduced in the Rheme in clause 1 gets promoted to become the Theme of clause 2" (Eggins, 2004, p.324). This pattern achieves cohesion in text to give a sense of a cumulative development which may be absent in the repeated theme pattern (Eggins, 2004, p. 325). This is shown below:

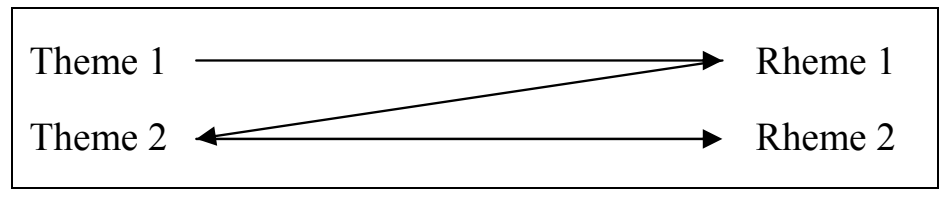

Figure 2, Zig-zag TP, Student A 1

Example: "However, Hall rejects accepting cultural identity $\mathbf{Z Z - Z}>$ is historically situated or a natural production through time. It $<\mathbf{Z}-\mathbf{Z}>$ is 'always constructed through memory, fantasy, narrative and myth' (Hall 1997, p53). Even though this understanding of identity is commonly referred to as being essentialised, it $<\mathbf{Z}-\mathbf{Z}>$ is an imaginary creation, not an essence captured from the past".

(3) Multiple-rheme pattern is when a number of different pieces of information are introduced in a rheme, "each of which is then picked up and made theme in subsequent clauses" (Eggins, 2004, p. 325). This is shown below: 


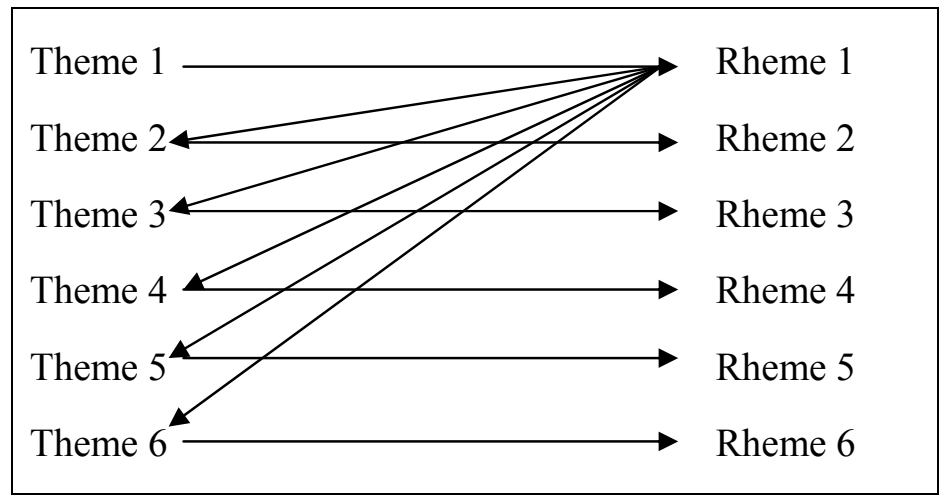

Figure 3, multiple-rheme, TP, Student A 1

Example: "In this sense, Culture is a systematic and definitive process of membership, a social system of identifiable inclusive and exclusive practices between the accepted, the 'insiders', and the excluded, the 'outsiders', the 'us' and 'others' (Kramsch, 1998; Woodward, 1997). This social construction of opposing categories of 'insiders' and 'outsiders' <M-R> are termed as binary oppositions which Hall (1997) maintains are the 'most extreme form of marking difference... essential to the production of meaning' (as cited in Woodward, 1997, p.35).

\subsection{Selection of Participants}

There were two main criteria in the process of the participant selection. The Iraqi participants must not have been educated in English-speaking or Western countries prior to their enrolment in the Australian M. TESOL course, and must have completed their first assignment for the unit within the year 2012. The Australian participants, in contrast, must not have been educated in Iraq or similar countries prior to their enrolment in the Australian M. TESOL, and also needed to have completed their first assignment for the unit within the same year. This study provides a descriptive and explanatory analysis of the nature of these writers' performance in their English academic assignments, based on the texts they produced.

\subsection{Unit of Analysis}

Using the T-unit as the basis of analysis, the four academic assignments were analysed using the theme-rheme framework (Eggins, 2004). The T-unit is defined by Fries (1994, p. 318) "as a clause complex which contains one main independent clause together with all the hypotactic clauses which are dependent on it". Analysing theme at the level of t-unit rather than the individual clauses make it easier to focus on patterns of the thematic development in large amounts of text, and can also be justified on the grounds that the thematic structure of a dependent clause is often constrained by the independent clause (Fries \& Francis, 1992).

\subsection{Procedure}

First of all, the four academic assignments were collected and the data were analysed based on Eggin's (2004) categorisation of thematic development. Secondly, the frequency of theme types in these academic segments was calculated. Thirdly, thematic progression in these written segments was tallied for each group, and after the instances of thematic progression 
were coded and tallied, the percentages were derived by comparing the number of their occurrences in each group of Iraqi and Australian postgraduate students' English writing (Eggins, 2004). One problem in discourse analysis is the danger of making mistakes in the data analysis and interpretations (Ebrahimi \& Ebrahimi, 2012). Therefore, to increase the reliability in this current study, one segment of each group was also analysed by an experienced researcher in applied linguistics and agreement was made on the method of analysis.

\section{Results and Discussion}

Table 1 illustrates the analysis of the thematic development patterns (theme reiteration, the zig-zag pattern, and the multiple-rheme pattern) and their proportions across the participants' texts. The analysis of the students' written segments helped to examine the strength and the weakness of the theme and rheme pattern choices in demonstrating the individual voice in the writers' critical argument in these segments of Iraqi and Australian postgraduate students' writing.

Table 1 Thematic Progression in the Students' Written Segments

Thematic Progression types Australian native writers (\%) Iraqi non-native writers (\%)

\begin{tabular}{lcccc}
\hline & Student A 1 & Student A 2 & Student Ir 1 & Student Ir 2 \\
\hline Theme Reiteration (T-R) & $2(5 \%)$ & $3(15 \%)$ & $11(34 \%)$ & $5(16 \%)$ \\
\hline Zig-Zag (Z-Z) & $6(16 \%)$ & $5(25 \%)$ & $6(19 \%)$ & $2(14 \%)$ \\
\hline Multiple Rheme (M-R) & - & $1(5 \%)$ & $1(3 \%)$ & - \\
\hline Total (in whole piece) & $37(100 \%)$ & $19(100 \%)$ & $32(100 \%)$ & $14(100 \%)$ \\
\hline
\end{tabular}

\subsection{The Functions of Theme Reiteration}

Table 1 illustrates that theme reiterations were more frequent in both segments of the Iraqi non-native writers (34\%). In the work of Student Ir 1, they occurred eleven times, and five times for Student Ir 2. In contrast, in the Australian native student writers' segments (15\%), the frequencies of theme reiteration occurred twice for Student A 1, and three times for Student A 2.

Example, 1 Student Ir 1

\begin{tabular}{ll}
\hline Theme Reiteration & Rheme \\
\hline Hall (1997b) $<$ T-R $>$ & proposed the term of "Diaspora" to refer to any \\
& migrants people that share common ethnic \\
& identity such as the African Diaspora in Europe.
\end{tabular}


Hall $<$ T-R $>$ refers to this diaspora and mentions that all cultural practices and forms of representation are putting the issue of cultural identity in question of" Who is this emergent" (p. 392).

Example, 2 Student Ir 2

\begin{tabular}{ll}
\hline Theme Reiteration & Rheme \\
\hline Hall (1979) $<$ TR $>$ & $\begin{array}{l}\text { argues that there is a diversity of meaning } \\
\text { through different cultures. }\end{array}$ \\
He (1997b) $<$ T-R $>$ & $\begin{array}{l}\text { focuses on "cultural practice" and suggests that } \\
\text { members in each culture usually give meaning to } \\
\text { people, objects, and events (p. 3). }\end{array}$ \\
He (1007b) $<$ T-R $>$ & $\begin{array}{l}\text { argues that members of specific culture represent } \\
\text { or interpret the meaning in different ways to suit } \\
\text { their culture. }\end{array}$ \\
\hline
\end{tabular}

Student Ir 1, a non-native writer, did not convey a critical analytical argument; rather he displayed and imitated Hall's ideas as a single dominating individual voice in his thematic development. This appears to be a problematic issue for the writer himself as he has not followed the assignment criteria as a requirement for his writing. One significant point deserving to mention is that his individual voice was unidentifiable as the sentence was a straightforward citation of other people's (Hall's) ideas. Further, although, Student Ir 1 used the "I" first-person pronoun in the third part of his written segment, this does not mean that this writer presented his self-voice in his writing. The student was instructed by the task to apply Hall's ideas to himself, yet this: "I" is his own voice in only this application function in his academic writing -he does not use it at all to critically discuss the work of others. This student used theme reiteration repeatedly in his segment. The repetition of this pattern may give the impression that his whole text was lacking in development and/or the ability to shift from one theme to another.

Example, 3 Student Ir 1

\begin{tabular}{ll}
\hline Theme Reiteration & Rheme \\
\hline For instance, I & $\begin{array}{l}\text { was an English language teacher in my home } \\
\text { country Iraq for three years. }\end{array}$ \\
Also I & $\begin{array}{l}\text { used to teach Arabic language in the Iraqi } \\
\text { community Arabic language school here in } \\
\text { Australia. }\end{array}$ \\
& a student at Monash University. \\
\hline
\end{tabular}


Indeed, the text of Student Ir 1 was difficult to follow since each part began in the same way, so that the reader has to always begin from the same spot without feeling the text is developing with the provision of new information. Student Ir 1 intended to evaluate Hall's argument in every theme as a key for his point of departure. However, using (Hall) repeatedly in consecutive sentences makes his text resemble a list of descriptive sentences, whereas the occurrence of (Hall) and (he) instead of abstract ideas in Student Ir 2's writing made his ideas difficult to identify in the segment. The latter student failed to express his own ideas with his own words. This finding is in line with Kamler and Thomson's (2006) study, which showed that when the theme remains constant and becomes difficult to follow this is because of the lack of rheme development (Eggins, 2004, see also Rusdinoor, 2009, p. 6, and Wang, 2007, p. 171), and is consistent with finding from previous research, which showed that Turkish EFL students in their essays writing were just copying and writing what they read from text rather than expressing their individual voice and supporting their claims with evidence (Alagozlu, 2007).

In the case of native writers, Students A 1 and A 2 use theme reiteration, but in low instances with a pattern of a complex set of linguistic strategies and focused information for these writers' written segments $(15 \%)$. Theme reiteration has been exploited with a great deal of authority and a dynamic planned progression in the presentation of their points of view. As shown below in Example 4, Student A2, the use of the theme reiteration occurs with more emphasis on the content of her argument and she did not rely merely on Hall's point of view; rather, she weaves in the views of other authors like Woodward to link implicitly her views with this other resource in an authoritative and effective way. This first theme is (identities), which appears several times in the theme of the following theme clauses resulting in a critical analytical argument rather than simply a descriptive one. This helped the writer to be authoritative in building up multiple voices of her own through confident expression of other resources with a very consistent pattern of building one upon the other. These results are in line with the research of Ramanathan and Atkinson (1999) who have indicated that in Western culture, achieving the cultural goal of independence requires one to reference an idea to one's own individual voice rather than by referencing it to the thoughts feelings, and actions only of others.

Example, 4 Student A 2

\begin{tabular}{ll}
\hline Theme Reiteration & Rheme \\
\hline Identity & $\begin{array}{l}\text { is marked out by differences between cultures } \\
\text { or group membership; }\end{array}$ \\
& $\begin{array}{l}\text { is subject to differences outside itself, specifically } \\
\text { to another identity which provides the conditions }\end{array}$ \\
\hline
\end{tabular}


of identity existence by what it is not (Woodward: 1997)

\subsection{The Functions of zig-zag Pattern}

The study found that the zig-zag pattern as a second part of thematic development occurred more frequently in the Australian native writers of English (25\%) than the Iraqi non-native writers (19\%). In the case of native writers of English, Student A 1, and A 2 used extended themes with effective zigzagging, an example of which is provided in example (5) Student A 1. Student A 1 used the information in the rheme of Sentence 1, "Cultural identity" as an unmarked ideational element that was, incorporated in the theme of the following sentences through the use of "it" in the following sentences. The student's purpose was to connect ideas between sentences and also to create a critical analytical argument. In this zig-zag pattern as a way of shaping cohesive text, the student was able to convey and create links between her information effectively and successfully for the reader. Indeed, according to Eggins (2004), using a zig-zag pattern helps achieve cohesive text "by building on newly introduced information" (p. 325). This finding is consistent with previous research (Eggins, 2004; Rusdinoor, 2009; Wang, 2007), which found that successful academic argumentative texts employ more cross-referential links from the rheme of one clause to the theme of the next clause. Therefore, when ideas result from an idea of the previous sentences, this can provide a coherent thematic development of argument in that text.

Kaplan (1966) contrasts the linearity in English academic writing with others organisational patterns of topic development such as the zig-zag. Although he associated the zig-zag patterning with writers of Middle Eastern languages, in the case of the present study, it was also found in the work of the Australians native writers of English who used more of the zig-zag pattern as a tool to keep cohesion and coherence in their written segments than did the non-native writers. This finding represents a critique of Kaplan's argument that the zig-zag pattern is characteristic of Arab students' writing, and contrasts to the linearity of English writers. This study showed that this pattern is also a characteristic of the Australian writers. At this point, I argue that it is possible to find varieties across cultures and stereotypes should not be held rigidly about each culture.

Example, 5 Student A 1

\begin{tabular}{|c|c|}
\hline Textual theme, Ideational theme & Rheme \\
\hline $\begin{array}{l}\text { However, Hall rejects accepting cultural } \\
\text { identity }\end{array}$ & $\begin{array}{l}\text { is historically situated or a natural production } \\
\text { through time }<\mathbf{Z}-\mathbf{Z}>\end{array}$ \\
\hline It $<$ Z-Z $>$ & $\begin{array}{l}\text { is 'always constructed through memory, fantasy, } \\
\text { narrative and myth' (Hall1997, p53). }\end{array}$ \\
\hline $\begin{array}{l}\text { Even though this understanding of } \\
\text { identity }\end{array}$ & $\begin{array}{l}\text { is commonly referred to as being essentialised } \\
<\mathbf{Z}-\mathbf{Z}>\end{array}$ \\
\hline it & $\begin{array}{l}\text { is an imaginary creation, not an essence captured } \\
\text { from the past }\langle\mathbf{Z}-\mathbf{Z}>\end{array}$ \\
\hline
\end{tabular}


In case of the non-native writers, the zigzag pattern has also been found in the segment of students Ir 1 and Ir 2, with this pattern appearing five times in the segment of Ir 2, and twice for Student Ir 1. As seen in Table 1, extended nominal groups were also found but were rarely used by Student Ir 2. It is worth mentioning that the low incidence of a zig-zag pattern in the segments of the Iraqi students could be because their EFL teachers focused almost exclusively on the word and sentence levels rather than the level of the whole academic written discourse. Another interpretation is that Students Ir 1 and Ir 2 were never taught to write academic texts even in Arabic. As a result they had not developed any higher frequency of zig-zag patterns in their English written segments. In short, this zig-zag pattern was difficult for them.

Example, 6 Student Ir 2

\begin{tabular}{|c|c|}
\hline Unmarked theme & Rheme \\
\hline This assumption & $\begin{array}{l}\text { is in contrast with what is claimed by Hall's } \\
\text { theory }\langle\mathbf{Z}-\mathbf{Z}>\end{array}$ \\
\hline $\begin{array}{l}\text { To summarise, Hall suggest that cultural } \\
\text { identity }\end{array}$ & $\begin{array}{l}\text { supplies a relation between individuals and other } \\
\text { people whom they live with and it combines how }\end{array}$ \\
\hline $\begin{array}{l}\text { Even though this understanding of } \\
\text { identity }\end{array}$ & $\begin{array}{l}\text { you see yourself and how others see you }<\mathbf{Z} \text {-Z }> \\
\text { is not only appointed by the connection how you } \\
\text { recognize yourself and how other people } \\
\text { recognize you but it is also by the connection }\end{array}$ \\
\hline This relation between others and you & $\begin{array}{l}\text { between what you want to be and the availability } \\
\text { of influences and opportunities }\langle\mathbf{Z}-\mathbf{Z}>\end{array}$ \\
\hline
\end{tabular}

\subsection{The Functions of Multiple-rheme}

In the case of multiple rheme, Table 1 shows that the total frequency of multiple rheme was similar for Student A 2 and Ir 1, but nil in Student Ir 2 and A 1. The multiple rheme patterns occur when the rheme and sometimes the theme of one clause introduce a number of different types of extended information for the whole text (Eggins, 2004). This makes the information provided by the writer in the text effective and well organized, increasing the accessibility of the persuasive argument for the reader. As Eggins (2004) suggested, the multiple rheme pattern provides the organisation principle for the whole text which is different from the other types of theme patterns like theme reiteration and zigzag pattern.

In the case of native writers, Student A 2 employed multiple theme patterns throughout her entire segment whereas Student A1 has not used that pattern at all. Example 7, illustrates how Student A 2 employed a multiple-rheme pattern within a single paragraph. Student A 2 used the rheme of the clause ( In this sense, culture) which is a marked theme by saying that culture "is a systematic and definitive process of membership, a social system of identifiable inclusive and exclusive practices between the accepted, the 'insiders', and the excluded, the 'outsiders', the 'us' and 'others' (Kramsch, 1998; Woodward, 1997). Here, in Example (7) Student A 2 introduces a number of different pieces of information, each of which is then picked up and made theme in subsequent clauses. The student has shown a critical eye in 
choosing from what she has read from the readings as a source for her assignment. Also, this informs the reader to expect that there is some extended information in the following clauses which is signalled by the extended rhemes. "This social construction of opposing categories of 'insiders' and 'outsiders' and 'Membership then becomes an instrument of inclusive and exclusive practice that people ally themselves to, entailing empowerment and endorsing control". The student makes the individual voice through self-reference in terms of "us and others", and avoided remaining distant from the argument. The student also supported her claims with adequate evidence from the texts in the form of citing authorities such as "Kramsch and Woodward" and with logical explanations rather than just reporting her claim in the form of proposals or definitions. This finding is consistent with those from previous research, which showed multiple rheme is another highly effective function, and valuable technique that skilled writers can used to enhance the connectivity (cohesion and coherence) in their piece of writing (Eggins, 2004).

Example, 7 Student A 2

Textual theme, Ideational theme

In this sense, Culture

\section{Rheme}

is a systematic and definitive process of

membership, a social system of identifiable inclusive and exclusive practices between the accepted, the 'insiders', and the excluded, the 'outsiders', the 'us' and 'others' (Kramsch, 1998; Woodward, 1997). are termed as binary oppositions which Hall (1997) maintains are the 'most extreme form of marking difference... essential to the production of meaning' (as cited in Woodward, 1997, p.35).

becomes an instrument of inclusive and exclusive practice that people ally themselves to, entailing empowerment and endorsing control.

In short, the analysis of multiple rheme shows that successful segments have the capacity to introduce a number of different pieces of information to link the writer' judgments with the other sentences in a very effective and consistent way. This means that these segments were written with great element of individual voice, rhetorical awareness, and this is adding textual cohesion for the entire number of written segments. This finding is consistent with those from previous research, which showed that a multiple rheme pattern is often one of the strong tools which can "provide the underlying organizing principle for a text" (Eggins, 2004, p. 326).

In comparison Student Ir 1 used only one multiple rheme pattern in his segment, and Student Ir 2 did not use multiple rhemes at all. In the case of Student Ir 1, he began his multiple rhemes pattern saying that there are two ways of thinking about cultural identity. His information was well managed and signalled by the textual themes the first way, and the 
second way. As mentioned in Example (8) (Student Ir 1, below, the writer used "textual themes" and the multiple rheme patterns were often also seen as a technique of using the textual themes. However, although the writer employed this kind of multiple rheme via textual themes in part of his written segment, they were still absent in the previous sentences. His multiple rhemes were like a patchwork of descriptive information rather than a re-organization of theme to persuade the reader of a particular argument. Thus, the student seems to have difficulties in producing claims of his own, which is related to the probable lack of individual voice.

Example, 8 Student Ir 1

\begin{tabular}{ll}
\hline Textual theme & Rheme \\
\hline Hall (1997b) & indicates two ways of thinking about cultural \\
& identity
\end{tabular}

The first way $<M-R>$

In the sense of this definition, cultural identity $<$ M-R $>$

The second way $<M-R>$ is the traditional model which views identity in terms of one shared culture.

reflects the common historical experiences and shared cultural codes that provide us with stable, unchanging, and continuous frames of reference and meaning.

of thinking about cultural identity, which Hall argues about, acknowledges the critical points of deep and significant difference.

\section{Conclusion}

The aim of this study was to investigate the development of individual voice through thematic development in academic assignments written by some Iraqi and Australian postgraduate students at Monash University. The data analysis indicated differences in the functional analysis of thematic development in terms of individual voice (Theme reiteration, zig-zag, and multiple-rheme) in these written segments. The study has shown that Iraqi postgraduate student' writers should keep in mind that, if they want to convey their individual voice when they write an academic text, function of the thematic development as a point of departure to form healthy academic argument.

Regarding thematic development, writers should pay attention to the following significant points:

Firstly, Iraqi postgraduate student writers should understand that using theme reiteration repeatedly will make their text difficult to follow for the reader and in turn this will cause their individual voice to be buried. In addition, following the texts of others only will prevent writers from forming a healthy original argument. Secondly, they should use a linear pattern 
in developing their argument to develop individual voice and to ensure that their readers are constantly with them in terms of thematic development. Thirdly, the study presents a critique of Kaplan's argument that the zig-zag pattern is characteristic of Arab students' writing, in contrast with the linearity of English writers. This study showed that this pattern is also a characteristic of the Australian writers. Variation in patterns is thus evident and stereotyped views of culture-bound patterns should not be held rigidly.

The result of this study will benefit teachers of English as a foreign language in Iraqi contexts as they consider how best to introduce the nature of English academic assignments and related strategies to students wishing to study overseas. As well, it will benefit the Iraqi English language students in teaching the individual voice elements in writing in Iraq. In turn this will help Iraqi postgraduate students to be fully acquainted with the standards of Western and Eastern academic writing requirements, and increase their familiarity with the specific genre as a global requirement for writing. All this will help them to become effective academic writers using discourse strategies like those of native speakers when it is appropriate to do so. Finally, the study reflects the differences of writing strategies used in the Australian and the Iraqi culture without the intention of reifying culturally-specific social practices or valuing one over the other. Instead, the intention was to urge educators and writers to combine both standards as this will enrich the competence of Iraqi postgraduate students in their writing.

\section{Acknowledgment}

I would have liked to offer my deepest gratitude and appreciation to my supervisor, Dr. Miriam Faine, for her patience and kindness and great support in challenging all the critical situations I had passed by throughout my research. I never forget her invaluable pieces of advice and I extremely appreciate all suggestions set by her at all the stages of the research-project. Also, I would like to extend my thanks to Dr. Rosemary Viete for her valuable editing this work and encouragement.

\section{References}

Alagozlu, N. (2007). Critical thinking and Voice in EFL writing. The Asian EFL Journal, 2, 118-136.http://asian-efl-journal.com/quarterly-journal/2007/09/28/critical-thinking-and-voice -in-efl-writing/\#thethe-tabs-1-2

Ahmed, A. A., (2010). Students' problem with cohesion and coherence in EFL essay writing in Egypt: Different perspectives. Literacy Information and Computer Education Journal (LICEJ),

1

(4),

212-221. http://www.infonomics-society.org/LICEJ/Students\%E2\%80\%99\%20Problems\%20with\%20 Cohesion\%20and $\% 20$ Coherence $\% 20$ in $\% 20$ EFL $\% 20$ Essay $\% 20$ Writing\%20in\%20Egypt_Diff erent $\% 20$ Perspectives.pdf

Al-Khasawneh, F. M. S. (2010). Writing for academic purposes: Problems faced by Arab postgraduate students of the college of business, UUM, ESP World, 9 (2), 1-23. http://www.esp-world.info/Articles_28/WRITING.pdf 
Barnawi, Z. (2011). Finding a place for critical thinking and self-voice in college English as a foreign language writing classrooms. English Language Teaching, 4 (2), 190-197. http://www.ccsenet.org/journal/index.php/elt/article/view/10790

Berry, M., (1995). “Thematic options and success in writing”. In Ghadessy M. (ed.) Thematic Development in English texts (p. 55-84). London \& New York: Pinter.

Ebrahimi, S., F. Ebrahimi, S., J. (2012). Point of departure in texts developed by native and non-native writers. Language in India, 12, (5), 1-5. http://www.languageinindia.com/may2012/foadpointofdeparture.pdf

Eggins, S. (2004). An introduction to systemic functional linguistics. London, England: Continuum.

Faculty of Education, Monash University (2013). Unit guide EDF 6236. Melbourne: Faculty of Education, Monash University. http://www.monash.edu.au/pubs/2013handbooks/units/EDF6236.html

Fries, P. H., \& Francis, G. (1992). Exploring theme: problems for research. Occasional Papers in systemic Linguistics, 6, (1), 45-60.

Halliday, M. A. K. (1985). An introduction to functional grammar. London: Edward Arnold.

Hyland, K. (2007). English for Professional academic purposes: Writing for scholarly publication, in D, Belcher (Ed): Teaching language purposefully: English for Specific $\begin{array}{llll}\text { Purposes in theory and } & \text { 1-8. }\end{array}$ http://www2.caes.hku.hk/kenhyland/files/2012/08/English-for-professional-academic-purpos es_writing-for-scholarly-publication.pdf

Ivanic, R., \& Camps, D. (2001). I am how I sound: Voice as self-representation in L2 writing. Journal of Second Language Writing, $10 \quad$ (1-2), 3-33. http://www.sciencedirect.com/science/article/pii/S1060374301000340

Jalilifar, A. (2009). Thematic development in English and translated academic texts, Journal of Language \& Translation, $10, \quad$ 81-111. https://www.academia.edu/8058272/Thematic_Development_in_English_and_Translated_Ac ademic_Texts

Jalilifar, A. R. (2010). The status of Theme in Applied Linguistic Articles. The Asian ESP Journal, $\quad 6(2), \quad$ 7-38. http://asian-esp-journal.com/journal-index/article-index/2010/168-october-2010-volume-6-iss ue-2-a-r-jalilifar

Johnson, A., Clerehan. , R. (2005). A Rheme of One's Own: How "Original' do we Expect Students to be?. Journal of University Teaching \& Learning Practise, 2 (3), 38-47. http://ro.uow.edu.au/jutlp/vol2/iss3/5/

Kaplan, R. B. (1966). Cultural thought patterns in intercultural education. Language Learning, 16, 1-20. http://ksuweb.kennesaw.edu/ djohnson/6750/kaplan.pdf 
Khalil, A. (1989). A study of cohesion and coherence in Arab EFL college students writing. System, 17(3), 359-371. http://www.sciencedirect.com/science/article/pii/0346251X89900080

Krisnawati, E. (2013). Applying theme and rheme in Indonesian EFL students' writing: An attempt to improve cohesion and coherence. The International Journal of Language and

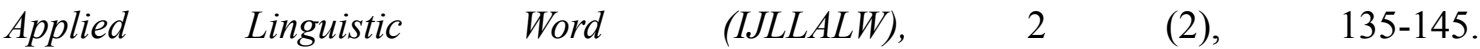
http://ecc.isc.gov.ir/ShwFArticle.aspx?aid=555412

Khuwaileh, A. ., \& Al Shoumali, A. (2000). Writing errors: a study of the writing ability of Arab learners of academic English and Arabic at university. Language, Culture, and Curriculum, $13(2)$,

174-183. http://www.tandfonline.com/doi/abs/10.1080/07908310008666597?journalCode=rlcc20\#.VG 8Ki9KUe8A

Kamler, Barbara and Thomson, Pat (2006) Helping doctoral students write: pedagogies for supervision, Routledge, London, England [A1].

Lewthwaite, M., D. (2010). Explore 'Coherence' in UGRU Student's Writing: Any Progress. UGRU Journal Spring, 10, 1-12.

Mellos, V. (2011). Coherence in English as a second language undergraduate writing: A theme-rheme analysis. (Unpublished master's thesis) San Diego State University, USA. http://scholarworks.calstate.edu/bitstream/handle/10211.10/1287/Mellos_Vickie.pdf?sequenc $\mathrm{e}=1$

North, S. (2005). Disciplinary variation in the use of theme in undergraduates' essays. Applied linguistics, 26 (3), 431-452.

Le Ha, P. (2009). Strategic, passionate, but academic: Am I allowed in my writing?. Journal $\begin{array}{llllr}\text { of English for Academic } & \text { Purposes, } & \text { 8, } & \text { 13-146. }\end{array}$ http://www.hum.uu.nl/medewerkers/m.c.j.kok-escalle/sites/competence_mediation/cursusdoc umenten/Phan\%20Le\%20Ha.pdf

Ramanathan, V., \& Atkinson, D. (1999). Individualism, academic writing, and ESL writers. $\begin{array}{lllll}\text { Journal of Second } & \text { Language } & \text { Writing, } & \text { 45-75. }\end{array}$ http://www.sciencedirect.com/science/article/pii/S106037439980112X

Rabab'ah, G. (2003). Communication problems facing Arab learners of English. Journal of Language and Learning, 3(1), 180-197. http://faculty.ksu.edu.sa/mdajani/Pages/ArabLearners.aspx

Rusdinoor, N. R. (2009). Thematic progression as a means to keep cohesion in exposition text. EBSS Journal, $12, \quad 1-9$. http://rusdinoor.wordpress.com/2009/12/12/thematic-progression-as-a-means-to-keep-cohesio n-in-exposition-text/

Viete, R. Phan, HL (2007). The growth of voice: Expanding possibilities for representing self in research writing. English Teaching Practice and Critique, 6 (2), 39-57. http://edlinked.soe.waikato.ac.nz/research/files/etpc/files/2007v6n2art3.pdf 


\section{Macrothink

Wang, L. (2007). Theme and rheme in the thematic organization of text: Implications for teaching academic writing. The Asian EFL Journal, 9 (1), 164-176. http:/asian-efl-journal.com/quarterly-journal/2007/03/28/theme-and-rheme-in-the-thematic-o rganization-of-text-implications-for-teaching-academic-writing/

\section{Copyright Disclaimer}

Copyright for this article is retained by the author(s), with first publication rights granted to the journal.

This is an open-access article distributed under the terms and conditions of the Creative Commons Attribution license (http://creativecommons.org/licenses/by/3.0/). 